\title{
Getting into hot water: sick guppies frequent warmer thermal conditions
}

\author{
Ryan S. Mohammed ${ }^{1,2} \cdot$ Michael Reynolds $^{1} \cdot$ Joanna James $^{1} \cdot$ Chris Williams $^{3}$. \\ Azad Mohammed $^{2} \cdot$ Adesh Ramsubhag $^{2} \cdot$ Cock van Oosterhout $^{4} \cdot$ Jo Cable $^{1} \mathbb{D}$
}

Received: 4 October 2015 / Accepted: 28 February 2016 / Published online: 10 March 2016

(c) The Author(s) 2016. This article is published with open access at Springerlink.com

\begin{abstract}
Ectotherms depend on the environmental temperature for thermoregulation and exploit thermal regimes that optimise physiological functioning. They may also frequent warmer conditions to up-regulate their immune response against parasite infection and/or impede parasite development. This adaptive response, known as 'behavioural fever', has been documented in various taxa including insects, reptiles and fish, but only in response to endoparasite infections. Here, a choice chamber experiment was used to investigate the thermal preferences of a tropical freshwater fish, the Trinidadian guppy (Poecilia reticulata), when infected with a common helminth ectoparasite Gyrodactylus turnbulli, in female-only and mixed-sex shoals. The temperature tolerance of G. turnbulli was also investigated by monitoring parasite population trajectories on guppies maintained at a continuous 18, 24 or $32{ }^{\circ} \mathrm{C}$. Regardless of shoal composition, infected fish frequented the $32{ }^{\circ} \mathrm{C}$ choice chamber more often than when uninfected, significantly increasing their mean temperature
\end{abstract}

Communicated by David Marcogliese.

M. Reynolds and J. James contributed equally to the study.

Jo Cable

cablej@ cardiff.ac.uk

1 School of Biosciences, Cardiff University, Cardiff CF10 3TL, UK

2 Department of Life Sciences, Faculty of Science and Technology, University of the West Indies, Mona, Trinidad and Tobago

3 National Fisheries Services, Environment Agency, Brampton, Cambridgeshire PE28 4NE, UK

4 School of Environmental Sciences, University of East Anglia, Norwich Research Park, Norwich NR4 7TJ, UK preference. Parasites maintained continuously at $32{ }^{\circ} \mathrm{C}$ decreased to extinction within 3 days, whereas mean parasite abundance increased on hosts incubated at 18 and $24{ }^{\circ} \mathrm{C}$. We show for the first time that gyrodactylid-infected fish have a preference for warmer waters and speculate that sick fish exploit the upper thermal tolerances of their parasites to self medicate.

Keywords Behavioural fever - Climate change - Thermal gradients $\cdot$ Trinidadian guppy $\cdot$ Gyrodactylus

\section{Introduction}

Temperature is perhaps the most important environmental determinant of the activity and performance of ectothermic vertebrates, and is particularly critical for fishes that, unlike amphibians and reptiles, are inefficient thermoregulators (Atkinson 1994). Fish behaviourally regulate their body temperature by selecting habitats with thermal regimes that optimise physiological performance (Reynolds et al. 1976; Ward et al. 2010). The metabolism, feeding rate and activity levels of ectotherms generally increase with temperature until conditions become stressful. Thermal stress can have long-lasting effects on fish behaviour with respect to migration (Jonsson and Jonsson 2009), reproductive success (Pankhurst and Munday 2011), predatory avoidance (Marine and Cech 2004), and shoaling (Weetman et al. 1998, 1999). For temperate fish, this results in marked seasonal and diel behaviours, but even tropical species are subjected to distinct temperature heterogeneities (Webb et al. 2008).

In addition to optimizing physiological performance, ectotherms exploit thermal regimes to hinder parasite transmission and development. A change in a host's 
thermal preference driven by pathogenic infection, otherwise known as 'behavioural fever', has been documented in several taxa including bumblebees (Müller and SchmidHempel 1993), locusts (Elliot et al. 2002), lizards (Vaughn et al. 1974) and fish. The first evidence of behavioural fever in fish was observed in largemouth bass (Micropterus salmoides) and bluegill sunfish (Lepomis macrochirus); both species displayed a significant increase $\left(+2.7^{\circ} \mathrm{C}\right)$ in mean temperature preference when inoculated with bacteria (Reynolds et al. 1976). This response was associated with bacterial pyrogens (fever-inducing chemicals) acting directly on the host's hypothalamic thermoregulatory centre (Reynolds et al. 1976). A subsequent study speculated that an increase in thermal preference by the fish host upregulates the immune response against parasite infection (Covert and Reynolds 1977). Using zebrafish (Danio rerio) infected with viraemia of carp virus it was confirmed that host behavioural fever induces a major up-regulation of the innate immune response, in this case expression of antiviral genes, which subsequently cleared viral infections within infected fish (Boltaña et al. 2013).

Acute thermal changes can be detrimental to the immune functions of fish (reviewed in Martin et al. 2010). However, some immune responses including elevations in lysozyme and immunoglobulin $\mathrm{M}$ levels are positively correlated with temperature until thermal limits are exceeded (Bowden et al. 2007; Marcos-Lopez et al. 2010). Thermal stress can reduce host immunocompetence thereby increasing disease susceptibility in ectotherms (Rohr and Raffel 2010). Interactions between these factors ultimately determine whether infections lead to severe pathology and even mortality, or host recovery. Parasites also respond directly to thermal variation, as elevated temperatures typically reduce development time. For example Schistocephalus solidus pleroceroid larvae, infecting three-spined sticklebacks, have faster growth rates and become infectious to their definitive host sooner at $20{ }^{\circ} \mathrm{C}$ compared to $15{ }^{\circ} \mathrm{C}$ (Macnab and Barber 2011).

For directly transmitted ectoparasites, including monogenean gyrodactylids, the rate of reproduction is positively correlated within a temperature range from 17 to $28{ }^{\circ} \mathrm{C}$ in tropical gyrodactylids, and $2.5-19.5{ }^{\circ} \mathrm{C}$ in temperate species (Scott and Nokes 1984; Jansen and Bakke 1991). Gyrodactylids are ubiquitous on teleosts, feeding on the skin and fin tissues of a host (Kearn 1996; Harris et al. 2004). Their life history traits, transmission and population dynamics have been extensively studied using the Trinidadian guppy-Gyrodactylus system (reviewed by Cable 2011). Gyrodactylus turnbulli, a common guppy ectoparasite, exhibits a viviparous reproductive strategy (Cable and Harris 2002), often resulting in explosive population growth, which can significantly impede host survival (e.g. Cable and van Oosterhout 2007a). As gyrodactylid embryonic development is temperature dependent (reviewed by Bakke et al. 2007), natural variations in water temperature can determine parasite population growth.

Whilst guppies exhibit broad temperature tolerance (Reeve et al. 2014), small changes in water temperature can dramatically modify gyrodactylid life history traits (Bakke et al. 2007), and temperatures exceeding $30{ }^{\circ} \mathrm{C}$ impede G. turnbulli survival (Scott and Nokes 1984). The present study investigates the thermal preferences of guppies in female-only and mixed-sex shoals, when uninfected and infected with the ectoparasite G. turnbulli. We also examine the temperature tolerance of these parasites by monitoring population trajectories on fish maintained at constant temperatures of 18,24 or $32{ }^{\circ} \mathrm{C}$. We hypothesize that guppies infected with G. turnbulli will frequent warmer water, in comparison to when they are uninfected, and exposure to extreme thermal conditions has benefits in terms of selfmedication against parasites.

\section{Materials and methods}

\section{Host and parasite origin}

Guppies from the Lower Aripo River, Trinidad, were collected in 2010 and stock populations were housed in breeding tanks at $24 \pm 0.5{ }^{\circ} \mathrm{C}$ at Exeter University. Fish were transferred to Cardiff University in April 2012 where they were maintained in 120 - $\mathrm{L}$ aquaria at $24 \pm 0.5{ }^{\circ} \mathrm{C}$ and fed daily on Aquarian ${ }^{\circledR}$ tropical fish flakes and occasionally frozen bloodworm.

The Gt3 strain of the parasite G. turnbulli was isolated from ornamental pet shop guppies in 1997, and was maintained on small numbers of fish (four to six individuals) in laboratory cultures at $24{ }^{\circ} \mathrm{C}$ under a 12-h light:12-h dark lighting regime. To prevent parasite extinction, each culture pot was subsidized with naïve fish twice weekly. Each pot contained a minimum of four culture fish collectively infected with approximately 40 gyrodactylid worms. To quantify mean parasite abundance (the total number of worms/the number of hosts including zero counts), guppies were anaesthetized with buffered $0.02 \%$ tricaine methanesulfonate (MS222) and screened using a dissecting microscope with fibre optic illumination. For experimental infections, a heavily infected donor fish from the parasite culture was sacrificed and two to six worms transferred through direct contact onto the caudal fin of an anaesthetized recipient fish, as observed using a dissecting microscope. To remove parasites, fish were chemically treated using $0.1 \%$ dilution of Levamisole (Norbrook, UK), and subsequently screened weekly over 3 consecutive weeks to ensure that the infection had been eliminated (see Schelkle et al. 2009). 




Fig. 1 The experimental arena consisted of three aquaria interconnected by two plastic tubes $(10 \mathrm{~cm}$ length $\times 4 \mathrm{~cm}$ diameter). The side walls of the arena were covered with black paper to reduce disturbance to the fish, with one side left open for observations. Tanks were filled with dechlorinated water to a depth of $15 \mathrm{~cm}$. Placing air stones, aquarium heaters and heating mats in and under each chamber

\section{Experimental set-up}

The experimental arena consisted of three plastic aquaria $(30 \times 20 \times 20 \mathrm{~cm})$ connected by two plastic tunnels (10 cm length $\times 4 \mathrm{~cm}$ DIA; Fig. 1). All tanks were filled with dechlorinated water to a depth of $15 \mathrm{~cm}$. The apparatus was covered by black paper on five sides to reduce disturbance by external stimuli, with one side left open to allow observations. The experiment was conducted in a temperature-controlled room $\left(15 \pm 0.5^{\circ} \mathrm{C}\right)$, under a 14 -h light:10-h dark lighting regime. Across the arena, a temperature gradient was established using heating mats under the central chamber (chamber B), and an aquarium heater in one side chamber (chamber C). Chambers A and B also contained small aquarium heaters that were not switched on to ensure uniform conditions within each chamber. Chamber A was maintained at $18 \pm 0.5^{\circ} \mathrm{C}$, chamber B at $24 \pm 1{ }^{\circ} \mathrm{C}$ and chamber $\mathrm{C}$ at $32 \pm 0.5^{\circ} \mathrm{C}$. Each chamber was uniformly aerated to prevent a thermocline developing within the tank.

\section{Experimental procedure}

Female-only (five females) or mixed-sex (three females, two males) shoals ( $n=14$ per shoal type) were placed in a $30 \times 15 \times 15-\mathrm{cm}$ aquarium to familiarise for 7 days prior to an experimental trial (according to Richards et al. 2010). Females typically form small shoals in the wild, between which males move in search of mating opportunities (Griffiths and Magurran 1998), hence the rationale for using female-only and mixed-sex shoals with natural sex ratios in the current study. Using a crossover experimental design, shoals (six female only and six mixed sex) were infected at the start of the trial and monitored for 2 days. On day 3 , these fish were artificially cleared of parasites and established a thermal gradient across the arena, and a consistent temperature within each tank. a Chamber A was maintained at $18{ }^{\circ} \mathbf{C}, \mathbf{b}$ chamber B at $24{ }^{\circ} \mathrm{C}$, and $\mathbf{c}$ chamber $\mathrm{C}$ at $32{ }^{\circ} \mathrm{C}$, each $\pm 0.5{ }^{\circ} \mathrm{C}$. b Fish were always introduced and returned to chamber $\mathrm{B}$ during an experimental trial

observed for a further 2 days. The remaining shoals (eight female only and eight mixed sex) started trials with uninfected individuals and were subsequently infected on day 3. Thus, each shoal served as its own infected/uninfected control, whilst the crossover design controlled for the potential effect of time by alternating the infection point. Experimental infections were conducted by housing each shoal with a heavily infected donor fish (>200 Gt3 worms) for 2 days in an infection tank $(20 \times 10 \times 10 \mathrm{~cm})$. Fish were then anaesthetized, and their gyrodactylid intensities recorded. To achieve a moderate infection (mean gyrodactylid intensity 22.5; range 13-34) per fish, additional worms were manually transferred to the caudal fin of some hosts from an infected donor fish (as previously described). Control fish were sham infected, whereby they endured the same handling and period of anaesthetisation, but were not exposed to parasites.

During a trial, either a female-only or mixed-sex shoal was introduced into chamber B of the arena. Profiles were created for each fish within a shoal documenting unique body colouration and markings enabling individuals to be distinguished. Over two consecutive days, each individual was observed five times per day with 2-h intervals in between. During a focal follow, fish in each chamber (A, $\mathrm{B}$ or $\mathrm{C}$ ) were recorded every $10 \mathrm{~s}$ for $1 \mathrm{~min}$, accumulating $10 \mathrm{~min}$ of observational data per fish. Individuals were then removed from the arena by scooping them up in a plastic $10 \times 10-\mathrm{cm}$ container to prevent parasite dislodgement, anaesthetised using $0.02 \%$ MS222 and screened for G. turnbulli using a dissection microscope with fibre optic illumination. Fish were then either experimentally infected, or their parasites chemically removed, thereby reversing their infection status. Following chemical treatment, individuals were screened to ensure no parasites remained on the host. At the end of a trial, these fish were screened 
twice more to ensure they were not infected, to confirm that they were parasite-free during the final days of observation. Uninfected fish were also exposed to levamisole and anaesthetic to account for their potentially confounding effects on fish behaviour. Fish monitoring was then resumed for a further 2 consecutive days. For these trials, fish were again introduced into chamber $\mathrm{B}$ of the experimental arena and allowed to habituate for $2 \mathrm{~h}$. This design allowed us to compare fish behaviour when the host was infected vs. uninfected, whilst also testing whether prior infection status influenced temperature preference.

\section{G. turnbulli temperature tolerance}

Parasite-naïve sexually mature experimental fish (>3 months old) were acclimated and maintained at water temperatures of 18,24 or $32{ }^{\circ} \mathrm{C}(n=20,37$ and 16 , respectively). This entailed increasing or decreasing daily water temperature by $1{ }^{\circ} \mathrm{C}$ for 8 or 6 days to reach 32 or $18{ }^{\circ} \mathrm{C}$, respectively. These fish were then maintained for a further 14 days under these conditions before being experimentally infected with two Gt3 worms on their caudal fin (according to the above protocol). Fish were individually housed in 1-L containers and screened daily over a 7-day period to record Gyrodactylus infection trajectories.

\section{Statistical analysis}

Analyses were conducted using $\mathrm{R}$ statistical software (version 3.1.3, R Development Core Team 2009). Statistical models were refined by deleting non-significant terms from the starting model, based on ANOVA (Crawley 2007).
Model robustness was assessed using residual plots (after Pinheiro and Bates 2000).

Using a generalised linear mixed model (GLMM), we investigated whether the mean temperature preference of fish was significantly different before and after infection. Temperature preference was the dependant term in the model and fixed effects included infection status (infected or uninfected), shoal type (female only or mixed sex), infection regime (fish infected at the beginning or second half of a trial) and standard length (millimetres). Fish identity was nested within shoal number and included as a random factor within the model. A negative binomial GLMM (glmmADMB statistical package) was used to investigate the effects of temperature, host standard length (millimetres), the day of infection (i.e. how many days a fish had been infected prior to a particular screen day), on gyrodactylid trajectories over the 7-day infection period. An interaction between temperature and the day of infection was also incorporated into the model, with Fish identity included as a random term.

\section{Results}

\section{Fish thermal preference}

Infection status had a significant effect on the mean temperature preference of fish [GLMM, likelihood ratio test $\left.(\mathrm{LRT})_{1,137}=819.97, P<0.0001\right]$, which was significantly higher when fish were infected (mean $=+0.97{ }^{\circ} \mathrm{C}$ ) than when uninfected (estimate $=-1.08, \mathrm{SE}=0.10$, $P<0.0001$; Fig. 2). Shoal type, standard length and
Fig. 2 The mean temperature preference of individual fish when infected with Gyrodactylus turnbulli, minus their mean temperature preference when uninfected $(n=138)$. Positive bars indicate individual fish that moved to warmer waters following infection, negative bars indicate individuals that moved to cooler waters when infected

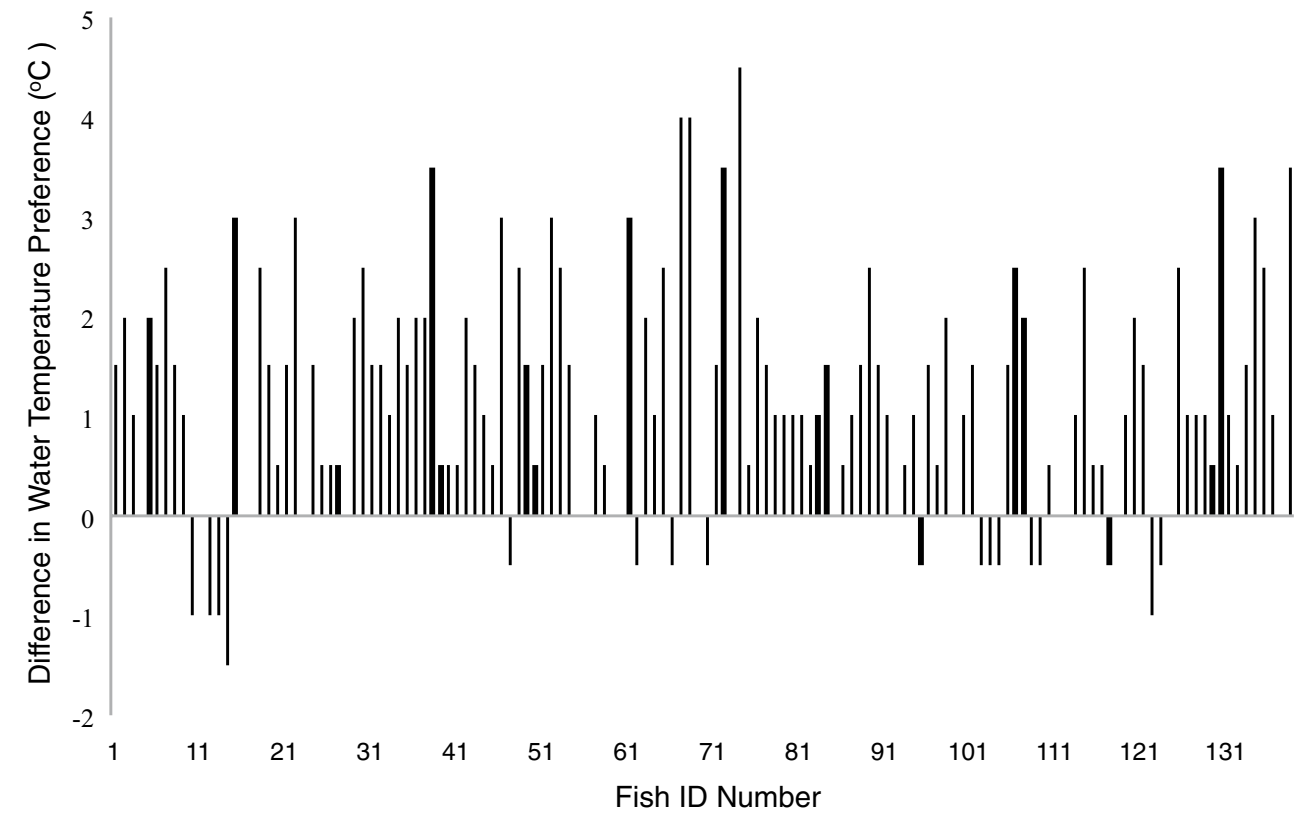




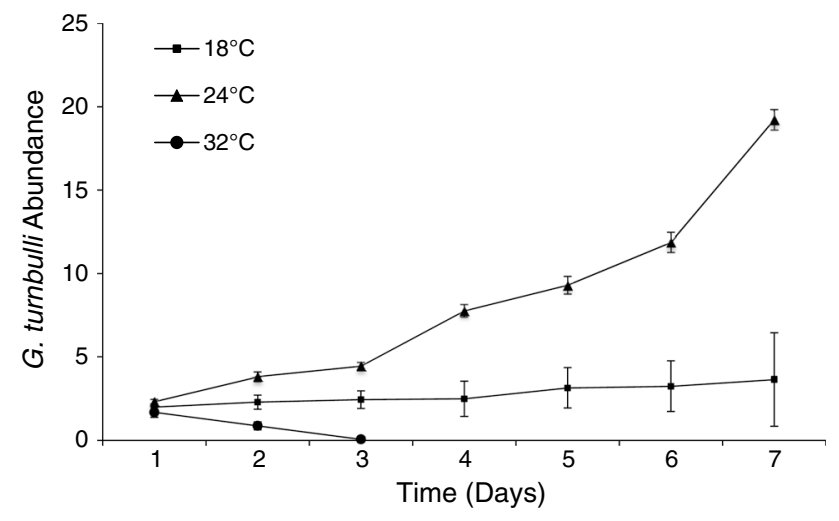

Fig. 3 Mean G. turnbulli abundance ( \pm SE) on guppies experimentally infected with two parasites on day 0 , and maintained at three different temperatures $\left(18,24\right.$ and $\left.32{ }^{\circ} \mathrm{C}\right)$ for a 7-day duration $(n=20$, 37 and 16 , respectively)

infection regime did not influence temperature preference $(P>0.05$ for all variables).

\section{G. turnbulli temperature tolerance}

Mean parasite abundance significantly increased over the 7-day infection period (GLMM, LRT $=638.70, d f=6$, $P<0.001)$; however, this was dependant on temperature (LRT $=75.76, d f=2, P<0.001)$. Parasite population increase was higher at $24{ }^{\circ} \mathrm{C}$, compared to $18{ }^{\circ} \mathrm{C}$ (estimate $=-0.95, \mathrm{SE}=0.22, P<0.0001)$ and $32{ }^{\circ} \mathrm{C}$ (estimate $=-3.01, \mathrm{SE}=0.29, P<0.0001)($ Fig. 3$)$.

\section{Discussion}

Here, we show for the first time that gyrodactylid-infected fish have a preference for warmer waters, and we speculate that fish exploit the upper thermal tolerances of their parasites to self-medicate against parasite infection. In addition, the guppy immune response may be up-regulated by the increase in temperature, which is consistent with the elevation of lysozyme and immunoglobulin M levels observed in other fish (Bowden et al. 2007). We also confirm the findings of Scott and Nokes (1984) that population growth of Gyrodactylus turnbulli is significantly impacted by temperature.

When exposed to a constant temperature, G. turnbulli infecting guppies at $32{ }^{\circ} \mathrm{C}$ declined to extinction within 3 days. Parasite mean abundance increased on fish maintained at 18 and $24{ }^{\circ} \mathrm{C}$; however, population growth was less pronounced in the $18{ }^{\circ} \mathrm{C}$ treatment. Despite G. turnbulli population growth being reduced at cooler temperatures, fish residing within such conditions may compromise the metabolic and immunological benefits of warmth.
This may explain why, when given a choice of three temperatures $\left(18,24\right.$ and $\left.32{ }^{\circ} \mathrm{C}\right)$, guppies frequented the $32{ }^{\circ} \mathrm{C}$ chamber more often compared to when uninfected; this was indicated by a significant increase in mean temperature preference. Three-spined sticklebacks infected with Schistocephalus solidus also exhibit a preference for warmer water in comparison to uninfected conspecifics. However, unlike our guppy-gyrodactylid system, this observed thermal shift promotes parasite growth, fecundity and ultimately transmission (Macnab and Barber 2011). The mechanisms involved in this seemingly maladaptive behavioural response are complex and, in the stickleback system, could be affected by both direct and indirect host behavioural manipulation by the parasite (Barber et al. 2004; Scharsack et al. 2007). Although gyrodactylids do cause behavioural changes in their hosts, these are almost certainly by-products of infection rather than parasitic host manipulation (e.g. Kolluru et al. 2009). Therefore, a significant increase in mean temperature preference is likely an adaptive host response. We speculate that this behavioural change directly imposes thermal stress on the parasite to increase mortality, as observed when parasites were maintained at a constant $32{ }^{\circ} \mathrm{C}$, and/or up-regulates the host's immune system to counteract gyrodactylid infection.

Guppies exhibit innate and acquired resistance to Gyrodactylus species; however, little is known about the precise mechanisms involved in guppy immunocompetence (Cable and van Oosterhout 2007b). Although the innate immune response of guppies is probably activated at the onset of $G$. turnbulli infection (Scott 1985; van Oosterhout et al. 2008), parasite population declines are most apparent 7-11 days post-infection at $25^{\circ} \mathrm{C}$. This is presumably associated with the induction of acquired immunity. Our results show that G. turnbulli infection did not persist for longer than 3 days on any hosts at $32{ }^{\circ} \mathrm{C}$. The failure of the parasite population at this temperature, particularly in such a short time, indicates that thermal stress, as opposed to the host immune defence, may be the predominant factor compromising parasite survival by impeding physiological function. The parasites used in the current study, however, were not acclimatised to the lower and upper temperature treatments prior to the experiment. Short generation times may facilitate rapid evolution of a wider thermal tolerance within gyrodactylids, although there is no empirical evidence to support this. Due to their small sizes and faster metabolic rates, parasites could acclimate faster than their hosts to thermal shifts, but only if physiological performance is improved at the acclimated temperature (Paull et al. 2015).

Guppies are native to Trinidad and Tobago where they typically reside in warm water ranging between $18-32{ }^{\circ} \mathrm{C}$ (Kent and Ojanguren 2015). They have a remarkable capacity for thermal adaptation with populations successfully establishing in environments with very different thermal 
regimes to their native habitats (Deacon et al. 2011). Water temperatures within freshwater streams can fluctuate by $\sim 10{ }^{\circ} \mathrm{C}$ daily (Reeve et al. 2014), and exposure to these temperature heterogeneities often results in marked behavioural changes. Juvenile guppies, for example, increase their average swimming speed and depth when exposed to elevated temperatures (Kent and Ojanguren 2015). Female guppies preferentially associate with larger, more cohesive shoals at high $\left(26^{\circ} \mathrm{C}\right)$ compared to low $\left(22{ }^{\circ} \mathrm{C}\right)$ water temperatures, particularly in the presence of cichlid predators (Weetman et al. 1998, 1999). Although associating with larger shoals may promote gyrodactylid transmission (Richards et al. 2010), by exploiting warmer thermal conditions, fish may self-medicate against parasite infection, particularly monogenean ectoparasites as shown here.

In summary, we use the guppy-G. turnbulli model to highlight how elevated temperatures can significantly impact host-parasite interactions within freshwater environments. G. turnbulli mean abundance increased at 18 and $28^{\circ} \mathrm{C}$, whilst thermal extremes of $32{ }^{\circ} \mathrm{C}$ caused population extinction. Additionally, it is shown how temperature selection by fish is influenced by parasite infection, with infected individuals frequenting warmer water more often than if uninfected. We speculate that this adaptive host behavioural response inhibits physiological functioning of gyrodactylid worms. This information helps us understand how existing natural variation in water temperature, at a local scale, influences disease outbreaks. In the future, we will be able to use such data to model how climate-driven population responses alter disease epidemics in wild and managed fish stocks within both tropical and temperate regions. Temperate species in particular face additional challenges associated with elevated temperature, including oxygen depletion within warmer water that subsequently impedes gill respiratory processes. Whether or not temperate species will tolerate thermal conditions outside their own temperature optima in order to self-medicate against parasite infection remains unknown.

Acknowledgments We thank Darren Croft for providing the original fish, Gabrielle Archard and Jess Stephenson for technical assistance, and two anonymous reviewers for their helpful comments on the manuscript.

Author contribution statement $\quad$ J. C. and C. W. designed the study; R. S. M. and J. J. collected the data; J. J., M. R. and C. O. performed the statistical analyses; M. R. drafted the manuscript; all authors commented on manuscript drafts.

\section{Compliance with ethical standards}

Conflict of interest The authors declare that they have no conflict of interest.

Ethical standards All applicable institutional and/or national guidelines for the care and use of animals were followed. Procedures and protocols were conducted under UK Home Office license (PPL 302876) with approval by the Cardiff University Animal Ethics Committee.

Open Access This article is distributed under the terms of the Creative Commons Attribution 4.0 International License (http://creativecommons.org/licenses/by/4.0/), which permits unrestricted use, distribution, and reproduction in any medium, provided you give appropriate credit to the original author(s) and the source, provide a link to the Creative Commons license, and indicate if changes were made.

\section{References}

Atkinson D (1994) Temperature and organism size: a biological law for ectotherms? Adv Ecol Res 25:1-58

Bakke TA, Cable J, Harris PD (2007) The biology of gyrodactylid monogeneans: the "Russian- Doll Killers". Adv Parasitol 64:161-376. doi:10.1016/S0065-308X(06)64003-7

Barber I, Walker P, Svensson PA (2004) Behavioural responses to simulated avian predation in female three spined sticklebacks: the effect of experimental Schistocephalus solidus Infections. Behaviour 141:1425-1440

Boltaña S, Rey S, Roher N, Vargas R, Huerta M, Huntingford FA, Goetz FW, Moore J, Garcia-Valtanen P, Estapa A, MacKenzie S (2013) Behavioural fever is a synergic signal amplifying the innate immune response. P R Soc B 280:20131381. doi:10.1098/ rspb.2013.1381

Bowden TJ, Thompson KD, Morgan AL, Gratacap RM, Nikoskelainen S (2007) Seasonal variation and the immune response: a fish perspective. Fish Shellfish Immunol 22:695-706. doi:10.1016/j.fsi.2006.08.016

Cable J (2011) Poeciliid Parasites. In: Evans JP, Pilastro A, Schlupp I (eds) Ecology \& Evolution of Poeciliid Fishes. Chicago University Press, Chicago, pp 82-94

Cable J, Harris PD (2002) Gyrodactylid developmental biology: historical review, current status and future trends. Int $\mathrm{J}$ Parasitol 32:255-280. doi:10.1016/S0020-7519(01)00330-7

Cable J, van Oosterhout C (2007a) The impact of parasites on the life history evolution of guppies (Poecilia reticulata): the effects of host size on parasite virulence. Int J Parasitol 37:1449-1458. doi:10.1016/j.ijpara.2007.04.013

Cable J, van Oosterhout C (2007b) The role of innate and acquired resistance in two natural populations of guppies (Poecilia reticulata) infected with the ectoparasite Gyrodactylus turnbulli. Biol J Linnean Soc 90:647-655. doi:10.1111/j.1095-8312.2006.00755.x

Covert JB, Reynolds WW (1977) Survival value of fever in fish. Nature 267:43-45. doi:10.1038/267043a0

Crawley MJ (2007) Statistical Modelling. In: Crawley MJ (ed) The R book. Wiley, England, pp 323-386

Deacon AE, Ramnarine IW, Magurran AE (2011) How reproductive ecology contributes to the spread of a globally invasive fish. PLoS One 6:e24416. doi:10.1371/journal.pone.0024416

Elliot SL, Blanford S, Thomas MB (2002) Host-pathogen interactions in a varying environment: temperature, behavioural fever and fitness. Proc R Soc Lond B 269:1599-1607. doi:10.1098/ rspb.2002.2067

Griffiths SW, Magurran AE (1998) Sex and schooling behaviour in the Trinidadian guppy. Anim Behav 56:689-693. doi:10.1006/ anbe.1998.0767

Harris PD, Shinn AP, Cable J, Bakke TA (2004) Nominal species of the genus Gyrodactylus von Nordmann 1832 (Monogenea: Gyrodactylidae), with a list of principle host species. Syst Parasitol 59:1-27. doi:10.1023/B:SYPA.0000038447.52015.e4 
Jansen PA, Bakke TA (1991) Temperature dependent reproduction and survival of Gyrodactylus salaris Malmberg, 1957 (Platyhelminthes: Monogenea) on Atlantic salmon (Salmo salar L.). Parasitology 102:105-112. doi:10.1017/S0031182000060406

Jonsson B, Jonsson N (2009) A review of the likely effects of climate change on anadromous Atlantic salmon Salmo salar and brown trout Salmo trutta, with particular reference to water temperature and flow. J Fish Biol 75:2381-2447. doi:10.1111/j.1095-8649.2009.02380.x

Kearn GC (1996) Evolutionary expansion of the Monogenea. Int J Parasitol 24:1227-1271. doi:10.1016/0020-7519(94)90193-7

Kent M, Ojanguren AF (2015) The effect of water temperature on routine swimming behaviour of new born guppies (Poecilia reticulata). Biol Open 4:547-552. doi:10.1242/bio.20149829

Kolluru GT, Grether GF, Dunlop E, South SH (2009) Food availability and parasite infection influence mating tactics in guppies (Poecilia reticulata). Behav Ecol 20:131-137. doi:10.1093/ beheco/arn124

Macnab V, Barber I (2011) Some (worms) like it hot: fish parasites grow faster in warmer water, and alter host thermal preferences. Global Change Biol 18:1540-1548. doi:10.111/j.1365-2486.2011.02575.x

Marcos-Lopez M, Gale P, Oidtmann BC, Peeler EJ (2010) Assessing the impact of climate change on disease emergence in freshwater fish in the United Kingdom. Transbound Emerg Dis 57:293-304. doi:10.1111/j.1865-1682.2010.01150.x

Marine KR, Cech JJ Jr (2004) Effects of high water temperature on growth, smoltification, and predator avoidance in juvenile Sacramento River chinook salmon. N Am J Fish Manage 24:198-210. doi: $10.1577 / \mathrm{M} 02-142$

Martin LB, Hopkins WA, Mydlarz LD, Rohr JR (2010) The effects of anthropogenic global changes on immune functions and disease resistance. Ann N Y Acad Sci 1195:129-148. doi:10.1111/j.1749-6632.2010.05454.x

Müller CB, Schmid-Hempel P (1993) Exploitation of cold temperatures as defence against parasitoids in bumblebees. Nature 363:65-67. doi:10.1038/363065a0

Pankhurst NW, Munday PL (2011) Effect of climate change on fish reproduction and early life history stages. Mar Freshwater Res 62:1015-1026. doi:10.1071/MF10269

Paull SH, Raffel TR, LaFonte BE, Johnson PTJ (2015) How temperature shifts affect parasite production: testing the roles of thermal stress and acclimation. Ecol, Funct. doi:10.1111/1365-2435.12401

Pinheiro JC, Bates DM (2000) Mixed-effects models in S and S-PLUS. Springer, New York

R Development Core Team (2009) R: A language and environment for statistical computing: the R Foundation for Statistical Computing. Vienna, Austria
Reeve AJ, Ojanguren AF, Deacon AE, Shimadzu H, Ramnarine IW, Magurran AE (2014) Interplay of temperature and light influences wild guppy (Poecilia reticulata) daily reproductive activity. Biol J Linnean Soc 111:511-520. doi:10.1111/bij.12217

Reynolds WW, Casterlin ME, Covert JB (1976) Behavioural fever in teleost fishes. Nature 259:41-42. doi:10.1038/259041a0

Richards EL, van Oosterhout C, Cable J (2010) Sex-Specific differences in shoaling affect parasite transmission in guppies. PLoS One 5:e13285. doi:10.1371/journal.pone.0013285

Rohr JR, Raffel TR (2010) Linking global climate and temperature variability to widespread amphibian declines putatively caused by disease. Proc Natl Acad Sci USA 107:8269-8274. doi:10.1073/pnas.0912883107

Scharsack JP, Koch K, Hammerschmidt K (2007) Who is in control of the stickleback immune system: interactions between Schistocephalus solidus and its specific vertebrate host. P R Soc B 274:3151-3158. doi:10.1098/rspb.2007.1148

Schelkle B, Shinn AP, Peeler E, Cable J (2009) Treatment of gyrodactylid infections in fish. Dis Aquat Organ 86:65-75. doi:10.3354/ dao02087

Scott ME (1985) Dynamics of challenge infections of Gyrodactylus bullatarudis Turnbull (Monogenea) on guppies, Poecilia reticulata (Peters). J Fish Dis 8:495-503. doi:10.1111/j.1365-2761.1985.tb00964

Scott ME, Nokes DJ (1984) Temperature-dependent reproduction and survival of Gyrodactylus bullatarudis (Monogenea) on guppies (Poecilia reticulata). Parasitology 89:221-227. doi:10.1017/ S0031182000001256

van Oosterhout C, Potter R, Wright H, Cable J (2008) Gyro-scope: an individual-based computer model to forecast gyrodactylid infections on fish hosts. Int J Parasitol 38:541-548. doi:10.1016/j. ijpara.2007.09.016

Vaughn LK, Bernheim HA, Kluger MJ (1974) Fever in the lizard Dipsosaurus dorsalis. Nature 252:473-474. doi:10.1038/252473a0

Ward AJW, Hensor EMA, Webster MM, Hart PJB (2010) Behavioural thermoregulation in two freshwater species. J Fish Biol 76:22872298. doi:10.1111/j.1095-8649.2010.02576.x

Webb BW, Hannah DM, Moore RD, Brown LE, Nobilis F (2008) Recent advances in stream and river temperature research. Hydrol Process 22:902-918. doi:10.1002/hyp.6994

Weetman D, Atkinson D, Chubb JC (1998) Effects of temperature on anti-predator behaviour in the guppy, Poecilia reticulata. Anim Behav 55:1361-1372. doi:10.1006/anbe.1997.0666

Weetman D, Atkinson D, Chubb JC (1999) Water temperature influences the shoaling decisions of guppies, Poecilia reticulata, under predation threat. Anim Behav 58:735-741. doi:10.1006/ anbe.1999.1191 